\title{
Desenvolvimento neuropsicomotor e o brincar de crianças em uma Unidade de Educação Infantil
}

\section{Neuropsychomotor development and play of children in a kindergarten school}

\author{
Natali Machado Pena Teixeira ${ }^{1}$, Priscila Barros Lourenço ${ }^{1}$, Elson Ferreira Costa ${ }^{1}$, \\ Luísa Sousa Monteiro Oliveira², Dalízia Amaral Cruz ${ }^{2}$
}

http://dx.doi.org/10.11606/issn.2238-6149.v30i2p116-123

Teixeira NMP, Lourenço PB, Costa EF, Oliveira LSM, Cruz DA. Desenvolvimento neuropsicomotor e o brincar de crianças em uma Unidade de Educação Infantil. Rev Ter Ocup Univ São Paulo. 2020 maio-ago.;30(2):116-23.

RESUMO: Este estudo teve como objetivo verificar a relação entre as características do brincar e o desenvolvimento neuropsicomotor de crianças de uma Unidade de Educação Infantil (UEI). Trata-se de uma pesquisa com delineamento longitudinal, de caráter descritivoexploratório, observacional e com abordagem quantitativa dos dados. Participaram 23 crianças, de ambos os sexos, com idade entre 3 e 4 anos, matriculadas em uma UEI do município de Belém-PA, em 2017. Para registro das características do brincar das crianças na escola foi utilizado o Protocolo de Observação do Brincar (POB) e para avaliação do desenvolvimento neuropsicomotor usou-se o Teste de Denver II. O estudo revelou que 56,5\% das crianças apresentaram o resultado suspeita de atraso no desenvolvimento. As variáveis do brincar que tiveram associação estatisticamente significativa com a suspeita de atraso no DNPM, a partir do Teste U de Mann-Whitney foram: interação em grupo $(p=0,04)$, brincadeira proposta pelo objeto $(p=0,03)$ e não brincadeira-exploração $(p=0,02)$. Considera-se que esta pesquisa possa contribuir para a identificação precoce de desvios no desenvolvimento de crianças no contexto escolar.

DESCRITORES: Desenvolvimento infantil; Jogos e brinquedos; Educação infantil.
Teixeira NMP, Lourenço PB, Costa EF, Oliveira LSM, Cruz DA. Neuropsychomotor development and play of children in a kindergarten school. Rev Ter Ocup Univ São Paulo. 2020 May-Aug.;30(2):116-23.

ABSTRACT: The purpose of this study was to verify the relationship between the characteristics of play and the neuropsychomotor development of children at Early Childhood School. It is a research with a longitudinal, descriptiveexploratory, observational and quantitative approach. Twenty-three children, both boys and girls, aged between 3 and 4 years, of a UEI of Belém-PA, participated in 2017. The Play Observation Protocol (POB) was used to record the characteristics of children's play in school, and the Denver II Test was used to evaluate neuropsychomotor development. The study revealed that $56.5 \%$ of the children had a suspected developmental delay. The play variables that had a statistically significant association with the suspected delay in DNPM from the Mann-Whitney U test were: group interaction $(\mathrm{p}=0.04)$, play proposed by the subject $(\mathrm{p}=0.03)$ and no prank-exploration $(p=0.02)$. It is considered that this research can contribute to the early identification of deviations in the development of children in the school context.

KEYWORDS: Child development; Play and playthings; Child rearing.

Este trabalho fez parte do Trabalho de Conclusão de Curso do Curso de Terapia Ocupacional da Universidade Federal do Pará, como critério estabelecido para obter grau de Bacharel em Terapia Ocupacional.

1. Universidade do Estado do Pará. ORCID: Teixeira NMP - https://orcid.org/0000-0003-1690-2909; Lourenço PB - https:/orcid.org/ 0000-0002-0206-9445; Costa EF - https://orcid.org/0000-0003-4115-9029; Email: nataly.jesus@yahoo.com.br, pbl08061991@hotmail.com, elsonfcosta@gmail.com.

2. Universidade Federal do Pará. ORCID: Oliveira LSM - https://orcid.org/0000-0002-3120-1839; Cruz DA - https://orcid.org/ 0000-0002-0474-7537.Emails: luisatomonteiro@gmail.com, liz.amaralcruz@gmail.com.

Endereço para correspondência: Departamento de Terapia Ocupacional, Universidade do Estado do Pará. Tv. Perebebuí, 2623 - Marco, Belém, PA. CEP: 66087-662. 


\section{INTRODUÇÃO}

$\mathrm{O}$ desenvolvimento neuropsicomotor (DNPM) é o processo sequencial da aquisição de um conjunto de funções e habilidades cognitivas, comportamentais e motoras, de acordo com a maturação do Sistema Nervoso Central e a idade cronológica. Essas características são resultantes da interação entre potencial biológico, genético, epigenético e do meio ambiente ${ }^{1}$.

No que diz respeito ao potencial ambiental, para as crianças que iniciam a vida escolar na primeira infância, a Unidade de Educação Infantil é um dos principais ambientes que elas participam e passam a maior parte de seu dia ${ }^{2}$, principalmente quando ficam em período integral. Dessa maneira, essas instituições são responsáveis por favorecer o desenvolvimento de forma global, sendo o brincar uma das estratégias usadas como ferramenta para a aprendizagem ${ }^{3,4}$.

Para a Terapia Ocupacional, o brincar é uma das principais ocupações da crianç̧ ${ }^{5-7}$ e pode ser utilizado como recurso potencializador do DNPM ${ }^{4,7,8}$. Essa ocupação é conceituada como atividade espontânea e organizada que ofereça satisfação e entretenimento ${ }^{9}$. Além disso, o brincar oportuniza a descoberta, a criatividade e a auto expressão, o que promove o desenvolvimento de habilidades nos diversos domínios do DNPM ${ }^{4,7}$. Deste modo, é essencial que o terapeuta favoreça o papel ocupacional de brincante e o desempenho ocupacional da criança ${ }^{5,7,10}$.

Os principais instrumentos de avaliação do desempenho da criança no brincar são: Histórico Lúdico; Escala Lúdica Pré-Escolar Modificada de Knox; Teste de Entretenimento; Escala de Brincar da Criança; e Simbolicand Imaginative Play Developmental Checklist. No entanto, Cordazzo et al. ${ }^{11}$ identificaram a necessidade da criação de um instrumento que caracterizasse o comportamento das crianças nas brincadeiras no contexto escolar e, para tanto, formularam o Protocolo de Observação do Brincar (POB), a fim de auxiliar professores e profissionais na área da saúde.

Diante disso, os terapeutas ocupacionais têm preferência pelo método de observação direta e entrevista com os pais durante a avaliação do brincar. Assim, é possível detectar atrasos no DNPM por meio das observações detalhadas no comportamento da criança no brincar e em seus ambientes de desenvolvimento ${ }^{10}$. Portanto, este profissional é apto a atuar na vigilância do desenvolvimento infantil e no desempenho ocupacional da criança, tanto com o brincar, quanto nas demais ocupações. Assim, o objetivo deste estudo é verificar a relação entre as características do brincar e o desenvolvimento neuropsicomotor de crianças de uma Unidade de Educação Infantil.

\section{PROCEDIMENTOS METODOLÓGICOS}

Trata-se de um estudo com delineamento longitudinal, de caráter descritivo-exploratório, observacional e com abordagem quantitativa dos dados.

\section{Contexto da Pesquisa}

O estudo foi realizado em uma Unidade de Educação Infantil (UEI) localizada no Distrito de Belém (DABEL), região central do município. Esta UEI recebe anualmente 75 crianças, divididas em três turmas (Maternal I, Maternal II e Jardim I). O atendimento ocorre em período integral $(7 \mathrm{~h} 30 \mathrm{~min}$ às $17 \mathrm{~h} 30 \mathrm{~min})$, acompanhado por dez professoras. O critério de seleção desta Unidade e dos participantes foi por amostragem não probabilística do tipo intencional ou julgamento.

\section{Participantes}

Participaram da pesquisa 23 crianças, sendo 13 do sexo masculino e 10 do sexo feminino, com idade entre três e quatro anos, matriculadas na turma do Maternal II, no ano de 2017. Ressalta-se que não houve a exclusão de crianças, pois nenhuma tinha alteração no desenvolvimento e todos os pais autorizaram a participação.

\section{Instrumentos}

Para avaliar o DNPM foi aplicado o Denver Developmental Screening Test - Denver II ${ }^{12}$, o qual avalia crianças entre zero a seis anos e está subdividido em quatro domínios: Pessoal-social, Motricidade Fina-Adaptativa, Linguagem e Motricidade Ampla. O teste é composto por 125 itens/tarefas que são administradas a partir da observação do examinador, embora alguns itens possam ser pontuados por declarações dos pais ou cuidadores. Os itens são interpretados como "passou", "falhou, "sem oportunidade" ou "recusou". Assim, é atribuída a pontuação "Normal/adequada", quando a criança "passa" na tarefa referente ao item; "Cautela", quando ela "falha" ou "recusa-se" a realizar uma tarefa cujos $75 \%$ a $90 \%$ das crianças da mesma idade, da população de referência, já realizava. Por fim, a pontuação "Atraso" é atribuída, quando a criança "falha" ou "recusa-se" a realizar uma tarefa na qual $90 \%$ das crianças ou mais já realizavam. A interpretação final do teste apresenta os indicadores: a) Normal/Adequado: quando não houver nenhum item de "atraso" ou, no máximo, um de "cautela"; b) Questionável: quando houver dois ou mais itens de "cautela" e/ou um de "atraso"; c) Atraso: quando a criança apresenta dois ou 
mais itens de "atraso", o que representa dizer que a criança apresenta suspeita de desvio no desenvolvimento, devendo ser reavaliada ou monitorada; d) Não testável: se houver marcações de "recusa" em um ou mais itens. A versão do Denver II traduzida e adaptada para o Brasil, aqui utilizada, foi a de Pedromônico et al. ${ }^{13}$.

Para registrar as características do brincar foi utilizado o Protocolo de Observação do Brincar (POB), elaborado por Cordazzo ${ }^{14}$ e Cordazzo et al. ${ }^{11}$. Este é dividido em três categorias: interação social, brinquedos e atividades. A categoria interação social é dividida em "não interação", que pode ser "solitária" ou "paralela" e "interação de grupo". A categoria "brinquedos" é dividida nas subcategorias: cognitivo, social, motor, e "sem brinquedo". A categoria "atividades" é classificada em tipos de brincadeiras (brincadeira construtiva, faz-de-conta, jogos de regras e brincadeira turbulenta) e não brincadeira (desocupado, observação, exploração, conversação e agressão). Há, também, a categoria "transição", a qual deve ser registrada quando a criança está mudando de atividade.

\section{Procedimentos de coleta de dados}

A coleta de dados ocorreu no período de março a junho de 2017. Os pais foram convidados a participar da pesquisa e a autorizar a participação dos filhos, com a assinatura do Termo de Consentimento Livre e Esclarecido (TCLE). A avaliação do desenvolvimento pelo Denver II foi realizada no refeitório da unidade, local mais reservado. Já a observação pelo POB foi realizada na sala de aula e no playground da unidade. As crianças foram observadas em sessões de brincadeira livre durante 30 minutos cada e em diferentes turnos. Foram realizadas técnicas de observação do sujeito focal e a do registro do comportamento por amostragem de tempo, conforme as normas do POB.

Para determinar a fidedignidade da coleta de dados, o primeiro momento destinou-se à realização do índice de concordância, no qual três observadores fizeram o registro das mesmas crianças e ao mesmo tempo. Este procedimento foi repetido até que se alcançasse $95 \%$ de concordância no preenchimento do POB. A partir daí, os dados foram registrados por dois observadores de forma independente, mas no mesmo momento.

Deste modo, em cada sessão, cada observador foi responsável por registrar os comportamentos de seis a dez crianças. A ordem de observação foi aleatória, mas combinada previamente. As crianças foram observadas, em forma de rodízio. Cada sujeito foi observado por cinco segundos e imediatamente era feito o registro no POB. Em seguida, era observada a segunda criança e assim por diante. Ao terminar o ciclo de todas as crianças, as pesquisadoras retornaram para a primeira criança e continuavam a sequência, até que todas fossem observadas 20 vezes por sessão. Foram realizadas 24 sessões no total.

As avaliações das crianças pelo Denver II foram realizadas em horários e dias previamente combinados com as professoras, respeitando-se os horários de atividades de rotinas e pedagógicas das crianças. Cada avaliação durou em média de 20 a 30 minutos por criança.

\section{Procedimentos de análise dos dados}

Os dados foram tabulados em planilhas de pacote estatístico e cada instrumento foi organizado a partir de seus eixos temáticos. Dessa maneira, foram realizadas análises descritivas e testes não paramétricos. Para verificar associações estatisticamente significativas entre as variáveis categóricas, usou-se o Teste de Fisher. E para comparar as diferenças entre as médias de meninos e de meninas no POB, aplicou-se o Teste $U$ de Mann-Whitney. Todos os testes tiveram nível de significância $\leq 0,05$.

\section{Considerações Éticas}

Este estudo foi aprovado pelo Comitê de Ética em Pesquisa do Núcleo de Medicina Tropical da Universidade Federal do Pará, pelo parecer 1.846.658/2016. Todos os procedimentos obedeceram à resolução $\mathrm{n}^{\circ} 466 / 2012$ do Ministério da Saúde para pesquisas com seres humanos. Além disso, houve a autorização da SEMEC para a realização da pesquisa e assinatura do TCLE pelos pais ou responsáveis.

\section{RESULTADOS}

Foram observadas 24 sessões de brincadeiras livres. Cada criança foi observada durante 20 intervalos de cinco segundos em cada sessão. A média de observações por criança foi de 16 sessões, o que totalizou 325,91 $(D P= \pm 28,40)$ intervalos de cinco segundos por criança, isto é, aproximadamente 27 minutos de observação para cada sujeito focal.

Quanto à categoria interação social, conforme Tabela 1, observou-se que meninos e meninas tiveram maiores médias na categoria "não interação paralela", ou seja, quando duas ou mais crianças brincam com o máximo de um metro de distância uma da outra, mas de forma independente ${ }^{11}$. A segunda maior média foi "interação em grupo", sendo as meninas com maior média. Já a menor média foi "não interação solitária", ou seja, quando a criança prefere brincar sozinha. 
Destaca-se, ainda, o resultado de segregação por sexo, um fenômeno no qual as crianças procuram parceiros do mesmo sexo para brincar. $\mathrm{O}$ teste $U$ de Mann-Whitney apontou diferença estatisticamente significativa para o total de interação com parceiras meninas $(p=0,04)$ e marginalmente significativa $(p=0,09)$ para o total de interação com parceiros meninos, ou seja, as crianças preferiam brincar com parceiros do mesmo sexo.

Tabela 1 - Médias de interação social entre as crianças

\begin{tabular}{|c|c|c|c|c|c|c|}
\hline \multicolumn{2}{|l|}{ Sexo } & \multirow{2}{*}{$\frac{\mathbf{N}}{10}$} & \multirow{2}{*}{$\begin{array}{c}\text { Média } \\
104.5\end{array}$} & \multirow{2}{*}{$\begin{array}{c}\text { Desvio-padrão } \\
96.2\end{array}$} & \multirow{3}{*}{$\begin{array}{c}\boldsymbol{U} \\
55,5\end{array}$} & \multirow{3}{*}{$\begin{array}{c}\text { p-valor } \\
0,43\end{array}$} \\
\hline Total não interação solitária & Feminino & & & & & \\
\hline & Masculino & 13 & 71.5 & 69.2 & & \\
\hline \multirow[t]{2}{*}{ Não interação paralela } & Feminino & 10 & 682.5 & 403.5 & \multirow{2}{*}{51,5} & \multirow{2}{*}{0,40} \\
\hline & Masculino & 13 & 543.9 & 363.6 & & \\
\hline \multirow[t]{2}{*}{ Total interação em grupo } & Feminino & 10 & 337.5 & 152.1 & \multirow{2}{*}{57} & \multirow{2}{*}{0,62} \\
\hline & Masculino & 13 & 319.7 & 311.1 & & \\
\hline \multirow[t]{2}{*}{ Total interação parceiros - meninos } & Feminino & 10 & 129.5 & 63.9 & \multirow{2}{*}{38} & \multirow{2}{*}{0,09} \\
\hline & Masculino & 13 & 315.3 & 273.8 & & \\
\hline \multirow[t]{2}{*}{ Total interação parceiros - meninas } & Feminino & 10 & 249.5 & 149.9 & \multirow{2}{*}{33} & \multirow{2}{*}{0,04} \\
\hline & Masculino & 13 & 138.8 & 130.4 & & \\
\hline
\end{tabular}

As situações de brincadeiras foram classificadas em cinco tipos, segundo o POB: proposta pelo objeto, faz-de-conta, construtiva, turbulenta e jogos de regras, conforme figura 1. $\mathrm{O}$ Teste $U$ de Mann-Whitney mostrou que houve diferenças significativas quanto à escolha do tipo de brincadeira faz-de-conta ( $p=0,05 ; U=36$ ), mais realizada pelas meninas e marginalmente significativa $(p=0,07 ; U=54)$ para brincadeiras turbulentas, mais praticadas pelos meninos. A partir das observações, destaca-se que as meninas geralmente brincavam de mãe e filha, casinha, panelinha e os meninos, quando brincavam de faz-de-conta, faziam o papel de trabalhador ou super-herói.

As escolhas dos tipos de brinquedos utilizados pelas crianças também foram analisadas, conforme Figura 1. O tipo de brinquedo mais utilizado pelas crianças, mas com maior percentual para as meninas, foi o de classificação cognitiva, que envolve intelecto e criatividade (desenhos, pinturas, massinha, blocos de encaixe), seguido pelo social (bonecos, telefone, panelinhas, carrinho). Estes dados relacionam-se com os anteriores, sobre os tipos de brincadeiras, visto que as meninas brincavam mais de faz-de-conta, logo utilizavam mais brinquedos de contingência social. Já os meninos, que brincavam mais de brincadeiras turbulentas, utilizavam mais brinquedos motores, como velocípedes e bolas ou sem brinquedos, quando estavam correndo, pulando, subindo nos móveis. Até mesmo no playground, observou-se diferença entre os sexos, pois os meninos tendiam a brincar nos brinquedos disponíveis (escorregador, balanço, cavalinho) ou de brincadeiras turbulentas de pega-pega e luta. As meninas também brincavam de faz-de-conta nesse espaço.

A categoria "não brincadeira" diz respeito aos momentos em que a criança está exercendo outros comportamentos como: desocupado, observando, explorando, conversando ou agredindo $^{11}$. Deste modo, verificou-se que o comportamento de não brincadeira mais frequente entres crianças foram "observação e conversação". Nesta categoria, apenas a variável "agredindo" apresentou diferença estatisticamente significativa ( $p=0,05 ; U=35,5)$, de acordo com o Teste Mann-Whitney $U$, mais frequente pelos meninos. O comportamento de agressão, segundo o POB, acontece quando a criança não está brincando e sim se dirigindo ao colega com algum tipo de violência ${ }^{11}$.

Em relação aos resultados do Denver II, $56,5 \%$ das crianças apresentaram o resultado suspeita de atraso e 43,5\% resultado normal, sendo a linguagem o domínio mais afetado $(52,2 \%)$, conforme Figura 2. Quanto ao sexo da criança, as meninas apresentaram menor percentual de suspeita de atraso no resultado global do Denver II (Meninas $=38,5 \%$; Meninos $=61,5 \%$ ) e na linguagem (Meninas $=33,3 \%$; Meninos $=66,7 \%$ ).

Nota-se que as variáveis que apresentaram associação estatisticamente significativa ou marginalmente significativa foram: "interação em grupo", "sem brinquedo", "brincadeira proposta", e "não brincadeira-exploração", conforme Tabela 3. 
Tipo de Brincadeira

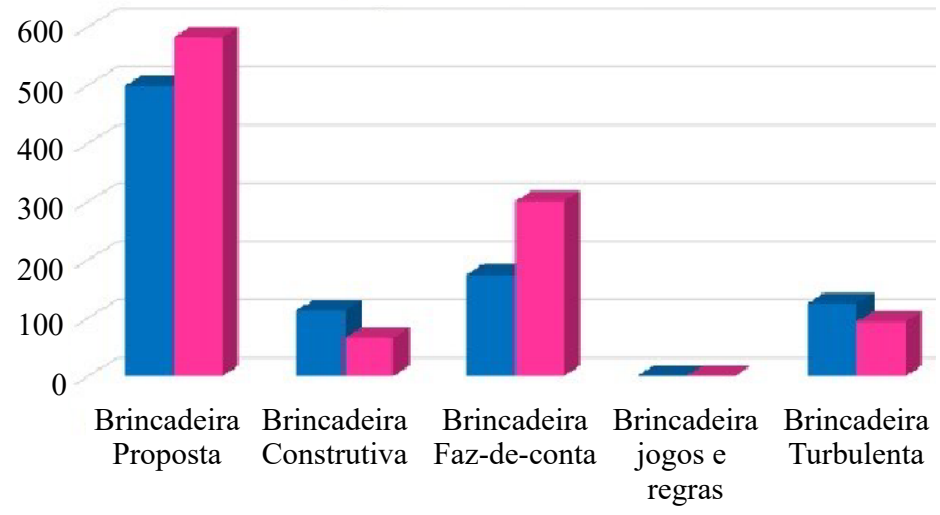

Tipo de Brinquedo

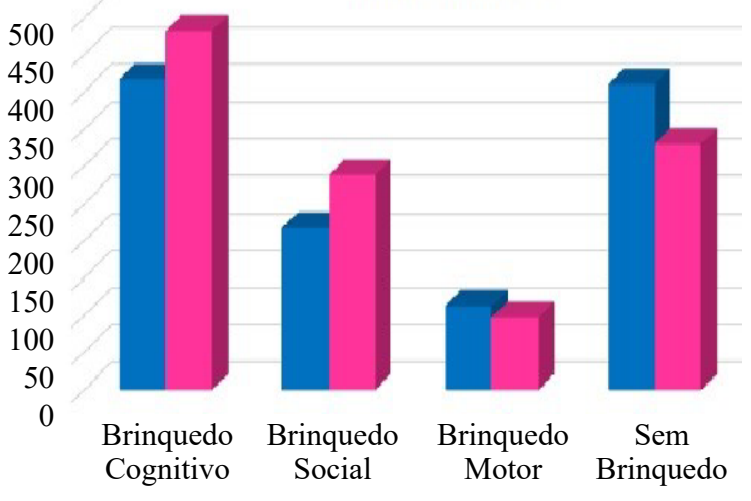

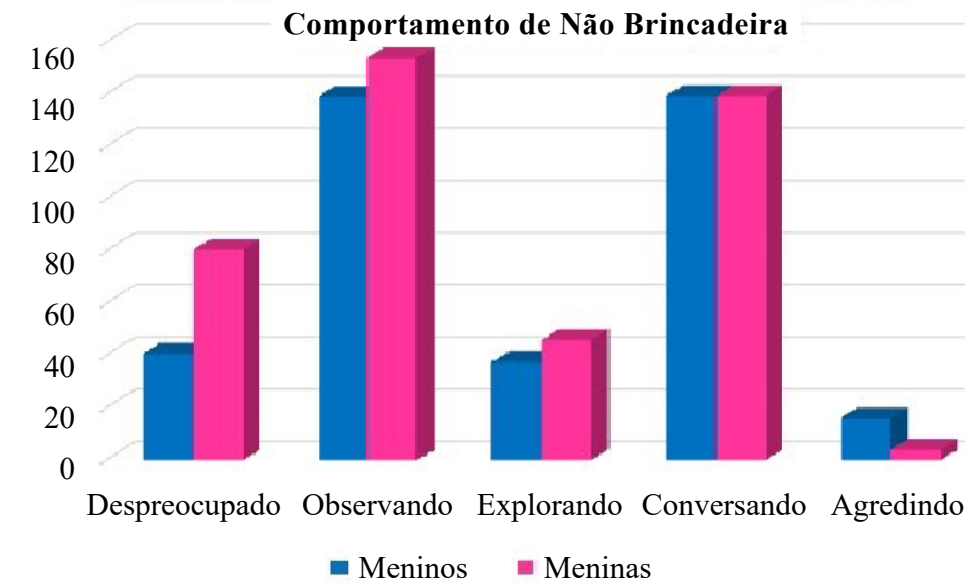

Figura 1 - Resultados do protocolo de observação do brincar

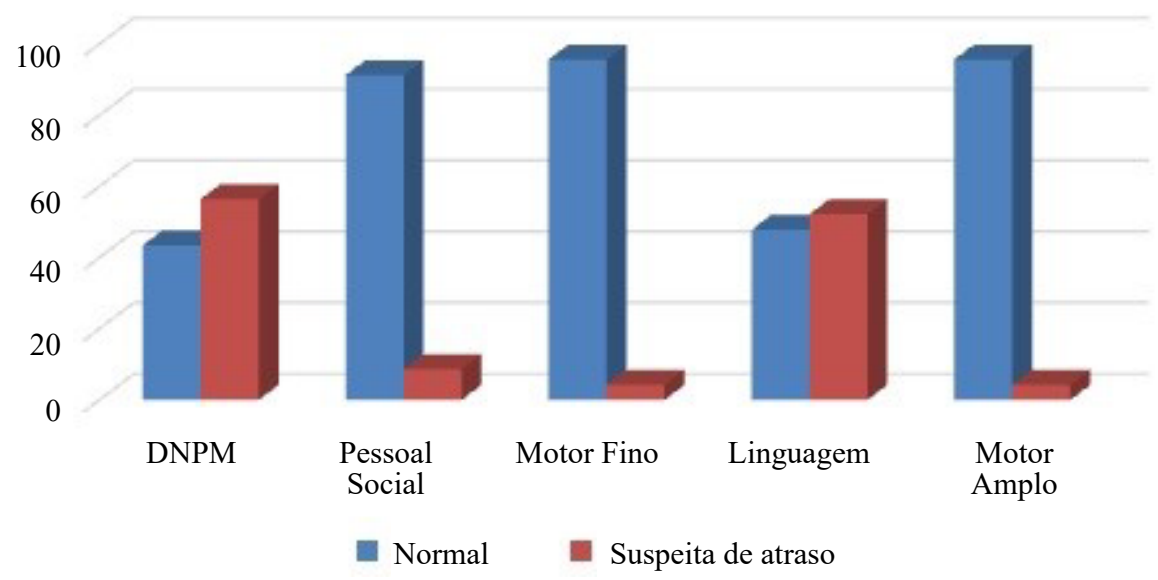

Figura 2 - Distribuição dos escores do Denver II 
Teixeira NMP, et al. Desenvolvimento neuropsicomotor e o brincar de crianças. Rev Ter Ocup Univ São Paulo. 2020 maio/ago.;30(2):116-23.

Tabela 3 -Distribuição das frequências dos intervalos de tempo observados em relação aos escores do Denver II

\begin{tabular}{|c|c|c|c|c|c|c|c|}
\hline \multirow{3}{*}{ POB } & \multirow{3}{*}{ Tempo (segundos) } & \multicolumn{4}{|c|}{ Denver II } & \multirow{3}{*}{ Fisher } & \multirow{3}{*}{$p$-valor } \\
\hline & & \multicolumn{2}{|c|}{ Normal } & \multicolumn{2}{|c|}{ Suspeita de Atraso } & & \\
\hline & & $\mathbf{N}$ & $\%$ & $\mathbf{N}$ & $\%$ & & \\
\hline \multirow[t]{4}{*}{ Interação em Grupo } & $0-245$ & 1 & 11.1 & 8 & 88.9 & & \\
\hline & $246-490$ & 6 & 66.7 & 3 & 33.3 & & \\
\hline & $491-735$ & 2 & 66.7 & 1 & 33.3 & 6,49 & 0,09 \\
\hline & $736-980$ & 1 & 50.0 & 1 & 50.0 & & \\
\hline \multirow[t]{4}{*}{ Sem Brinquedo } & $0-230$ & 0 & 0.0 & 7 & 100.0 & & \\
\hline & $231-460$ & 6 & 66.7 & 3 & 33.3 & 11,6 & 0,009 \\
\hline & $461-690$ & 4 & 80.0 & 1 & 20.0 & & \\
\hline & $691-920$ & 0 & 0.0 & 2 & 100.0 & & \\
\hline \multirow{4}{*}{$\begin{array}{l}\text { Brincadeira } \\
\text { Proposta }\end{array}$} & $0-253$ & 0 & 0.0 & 6 & 100.0 & & \\
\hline & $254-507$ & 3 & 75.0 & 1 & 25.0 & 8,70 & 0,03 \\
\hline & $508-760$ & 5 & 71.4 & 2 & 28.6 & & \\
\hline & $761-1015$ & 2 & 33.3 & 4 & 66.7 & & \\
\hline \multirow[t]{4}{*}{ Exploração } & $0-20$ & 1 & 10.0 & 9 & 90.0 & & \\
\hline & $21-40$ & 2 & 66.7 & 1 & 33.3 & & \\
\hline & $41-60$ & 2 & 100.0 & 0 & 0.0 & 8,99 & 0,02 \\
\hline & $61-80$ & 5 & 62.5 & 3 & 37.5 & & \\
\hline
\end{tabular}

\section{DISCUSSÃO}

Em relação ao Denver II, verificou-se que o resultado foi acima de $50 \%$ de suspeita de atraso. Na revisão sistemática realizada por Lima et al. ${ }^{15}$, foram analisados 31 artigos brasileiros, os quais apresentaram percentual de suspeitas de atraso entre 0 a $46,3 \%$ para crianças típicas e $14,2 \%$ a $100 \%$, para atípicas. Ao comparar esses dados com o deste estudo, veri ica-se que as crianças participantes tiveram percentual de suspeita de atraso acima de $50 \%$. No entanto, em outros estudos, foram encontrados resultados semelhantes ao desta pesquisa ${ }^{2,16}$.

Os dados deste estudo mostraram que as crianças brincavam mais individualmente do que com os pares. Tal resultado pode ter sido influenciado pelo direcionamento do brincar realizado pelas professoras, observou-se que tal comportamento era frequente, eram dadas instruções sobre qual brinquedo usar ou qual brincadeira realizar, sendo pouco estimulado o brincar livre e em grupo. De modo geral, foi observado que as crianças que brincaram menos tempo em grupo, tiveram maior percentual de suspeita de atraso pelo Denver II. Como hipótese explicativa, destaca-se que, por meio do brincar em grupo, as crianças desenvolvem habilidades sociais ${ }^{4,17}$ como empatia, assertividade e civilidade, do contrário, elas podem precisar de mais estímulos desenvolvimentais.
Quanto a segregação por sexo, resultados semelhantes foram encontrados nos estudos de Cordazzo et al. ${ }^{8,11}$, Cordazzo $^{14}$, Wong e Yeung ${ }^{17}$ e Chapman ${ }^{18}$. As hipóteses explicativas para esse resultado estão relacionadas, principalmente, às questões culturais. Isto é, desde a primeira infầncia são constituídos rótulos ou estereótipos de gênero e/ ou sexo, formuladas por agentes socializadores (pais, professores, cuidadores, entre outros), que estabelecem brinquedos e brincadeiras masculinos e femininos ${ }^{14,17-19}$. Em consequência disso, pode resultar a diferença quanto aos papéis sociais, sendo as meninas mais incentivadas a realizar atividades que estimulam habilidades de motricidade ina e linguagem e os meninos a motricidade ampla $^{2}$. Os dados do presente estudo corroboram com a literatura, pois prevaleceu o envolvimento das meninas em brincadeiras simbólicas que foi relacionado ao melhor desempenho na linguagem e motricidade ina. Já os meninos engajaram-se mais em brincadeiras turbulentas, o que pode ter favorecido o desempenho na motricidade ampla.

Outros estudos ${ }^{18,20}$ têm destacado a preferência de meninas por brincadeiras sociais e simbólicas como o faz-de-conta. Já os meninos, têm demonstrado interesse por brincadeiras de contingência física ou turbulentas ${ }^{8}$. Além disso, o comportamento de agressão na brincadeira, comum entre os meninos, também tem sido associado a brincadeiras turbulentas ${ }^{21}$. 
As crianças que mais foram observadas sem brinquedos também apresentaram maior percentual de suspeita de atraso no DNPM, principalmente na linguagem. Pode-se considerar a hipótese de o brinquedo ser um estímulo material necessário à imaginação e dá o suporte para a brincadeira, ou seja, motiva a criança a manter-se engajada no brincar e viabiliza o desenvolvimento nas diversas dimensões ${ }^{3,14}$. Em contrapartida, as crianças que brincaram mais de brincadeira proposta tiveram melhores percentuais de desenvolvimento dentro da normalidade, segundo o Denver II. As brincadeiras propostas, segundo o $\mathrm{POB}$, são aquelas que a criança brinca seguindo as sugestões do fabricante ${ }^{14}$. Por fim, destaca-se que o comportamento de exploração também apresentou associação estatisticamente significativa. As crianças que se envolveram mais nesta categoria apresentaram melhores resultados no Denver II.

Ao que concerne à Terapia Ocupacional, Nunes et al. ${ }^{22}$ afirmam que por meio da diversidade de brincadeiras, o desenvolvimento vai se processando, sendo moldado conforme a qualidade das interações envolvidas nas trocas sociais e por suas ocupações cotidianas, que proporcionarão potencialidades singulares a criança. Assim, compreender o brincar viabiliza a obtenção de conhecimentos a respeito do desempenho ocupacional, desenvolvimento geral e relacional do indivíduo ${ }^{22}$. No estudo de Fonseca e Silva ${ }^{7}$, constatouse que o brincar é bastante valorizado na prática clínica da Terapia Ocupacional. A maioria dos terapeutas ocupacionais utiliza o brincar como ferramenta de intervenção e estímulo de habilidades neuropsicomotoras e do desempenho ocupacional.

\section{CONCLUSÕES}

Este estudo verificou a relação entre as características do brincar e o desenvolvimento neuropsicomotor de crianças de uma Unidade de Educação Infantil do município de Belém. Por meio da análise dos resultados, pôde-se verificar que a maioria das crianças apresentou suspeita de atraso no DNPM, sobretudo na linguagem, segundo o Denver II. Além disso, as crianças que apresentaram menor tendência a brincar em grupo e que menos utilizaram brinquedos, tiveram maior percentual de suspeita de atraso. Já as crianças, que brincaram mais de brincadeira proposta pelo objeto ou que tinham mais comportamentos de exploração, apresentaram melhor desempenho no DNPM. Observou-se, ainda, a predominância da interação entre crianças do mesmo sexo durante as brincadeiras.

Esses resultados destacam a importância de que observar as crianças durante as brincadeiras no ambiente escolar e o uso de testes de triagem do DNPM podem auxiliar os profissionais da educação e da saúde a obterem conhecimentos sobre as características do desenvolvimento infantil. Com isso, pode-se identificar mais rapidamente quais crianças apresentam algum desvio no DNPM e encaminhá-las à intervenção mais adequada. Destaca-se também o papel que o terapeuta ocupacional poderia ter em uma UEI, no acompanhamento do DNPM e o favorecimento de atividades diárias significativas, como o brincar. Além disso, nossos resultados podem contribuir para o incentivo à estimulação da brincadeira livre nesses ambientes, e a implementação de políticas públicas neste contexto, com vistas à triagem e acompanhamento do neurodesenvolvimento.

Quanto às limitações, destaca-se o tamanho da amostra, a baixa assiduidade de alguns participantes e o pouco incentivo para brincadeiras livres na UEI, o que dificultou a coleta de dados. Os autores consideram a necessidade do desenvolvimento de novos estudos, preferencialmente com amostra probabilística e o uso da metodologia qualitativa para melhor investigação deste fenômeno.

Participação dos autores: Natali Machado Pena Teixeira e Priscila Barros Lourenço; participaram da elaboração do projeto, coleta de dados e elaboração do manuscrito. Elson Ferreira Costa: participou como orientador do projeto de pesquisa, da análise dos dados e elaboração do texto final do manuscrito. Luísa Sousa Monteiro Oliveira: participou da elaboração do texto final do manuscrito. Dalizia Amaral Cruz: realizou a revisão ortográfica e gramatical e elaboração do texto final do manuscrito. 
Teixeira NMP, et al. Desenvolvimento neuropsicomotor e o brincar de crianças. Rev Ter Ocup Univ São Paulo. 2020 maio/ago.;30(2):116-23.

\section{REFERENCIAS}

1. Araújo LB, Israel VL, editores. Desenvolvimento da criança: família, escola e saúde. Curitiba: Omnipax; 2017.

2. Silva ML, Cavalcante LIC, Heumann S, Lima, TVR. Relação entre gênero e desempenho neuropsicomotor de crianças em Belém, Brasil. Ciênc Saúde Coletiva. 2018;23(8):2721-30. http://dx.doi.org/10.1590/1413-81232018238.13202016.

3. Kishimoto TM, Santos MW, organizadores. Jogos e brincadeiras tempos, espaços e diversidade (pesquisas em educação). São Paulo: Cortez Editora; 2017.

4. Teixeira H, Volpini M. A importância do brincar no contexto da educação infantil: creche e pré-escola. Cad Educ Ens Soc (Bebedouro). 2014;1(1):76-88. Disponível em: http://www.unifafibe.com.br/revistasonline/arquivos/ cadernodeeducacao/sumario/31/04042014074001.pdf.

5. Zen C, Omairi C. O modelo lúdico: uma nova visão do brincar para a terapia ocupacional. Cad Ter Ocup UFSCar. 2009;17(1):43-51. Disponível em: http://www. cadernosdeterapiaocupacional.ufscar.br/index.php/cadernos/ article/view/117/75

6. Brunello M, Mieto F, Silva C. Procedimentos de avaliação da qualidade do brincar na prática da terapia ocupacional: um estudo exploratório. Rev Ter Ocup USP. 2013; 24(2):95102. https://doi.org/10.11606/issn.2238-6149.v24i2p95-102.

7. Fonsêca M, Silva Â. Concepções e uso do brincar na prática clínica de terapeutas ocupacionais. Cad Ter Ocup UFSCar. 2015;23(3):589-597. http://dx.doi.org/10.4322/0104-4931. ctoAO0554.

8. Cordazzo S, Westphal J, Tagliari F, Vieira M. Brincadeira em escola de ensino fundamental: estudo observacional. Inter Psicol. 2010:14(1):43-52. http://dx.doi.org/10.5380/ psi.v14i1.14299

9. AOTA - American Occupational Therapy Association. Estrutura da prática da terapia ocupacional: domínio \& processo. $3^{\mathrm{a}}$ ed. Traduzida. Rev Ter Ocup Univ São Paulo. 2015;26(ed. Esp.):1-49. https://doi.org/10.11606/issn.22386149.v26iespp1-49.

10. Pinheiro, MFG, Gomes, CL. Abordagens do brincar em cursos de graduação na área da saúde: educação física, fisioterapia e terapia ocupacional. Movimento. 2016;22(2):555-65.

11. Cordazzo S, Westphal J, Tagliari F, Vieira M, Oliveira A. Metodologia observacional para o estudo do brincar na escola. Aval Psicol. 2008;7(3):427-38. Disponível em: http:// pepsic.bvsalud.org/scielo.php?script=sci_arttext\&pid=S167704712008000300014\&lng=pt.
12. Frankenburg WK, Dodds J, Archer P, Shapiro H, Bresnick B. DENVER II: training manual. 2nd ed. Denver, USA: Denver Developmental Materials; 1992.

13. Pedromônico MRM, Bragatto EL, Strobilus R. Teste de triagem de Denver II. São Paulo: Universidade Federal de São Paulo; 1999.

14. Cordazzo S. Influência do brincar no desempenho motor, cognitivo e social de crianças em idade escolar no Brasil e em Portugal [Tese]. Florianópolis, SC: Universidade Federal de Santa Catarina; 2008. Disponível em: http://repositorio. ufsc.br/xmlui/handle/123456789/91645.

15. Lima S, Cavalcante L, Costa E. Triagem do desenvolvimento neuropsicomotor de crianças brasileiras: uma revisão sistemática da literatura. Fisioter Pesqui. 2016;23(3):33642. http://dx.doi.org/10.1590/1809-2950/15703523032016.

16. Coelho R, Ferreira JP, Sukiennik R, Halpern R. Child development in primary care: a surveillance proposal. J Pediatr (Rio J). 2016;92(5):505-11. https://doi.org/10.1016/j. jpedp.2016.05.016.

17. Wong WI, Yeung SP. Early Gender Differences in Spatial and Social Skills and Their Relations to Play and Parental Socialization in Children from Hong Kong. Arch Sex Behav. 2019;48(5):1589-602. https://doi-org/10.1007/s10508-0191415-8.

18. Chapman, R. A case study of gendered play in preschools: how early childhood educators' perceptions of gender influence children's play. Early Child Deve Care. 2016;186(8):1271-84. https://doi-org/10.1080/03004430.2015.1089435.

19. Bicalho C. Brincadeiras infantis e suas implicações na construção de identidades de gênero. Rev Med Minas Gerais. 2013;23(2):41-9. https://doi.org/10.5935/2238-3182.2013S007.

20. Oliveira L, Reis D, Magalhães C, Pedroso J. Estudo comparativo entre contextos de brincadeiras em instituição de acolhimento infantil. Rev Psicol. 2015;46(3):311-20. http:// dx.doi.org/10.15448/1980-8623.2015.3.17978.

21. Lansford J, Skinner AT, Sorbring E, Di Giunta L, DeaterDeckard K, Dodge KA, et al. Boys' and girls' relational and physical aggression in nine countries. Aggress Behav. 2012;38(4):298-308. http://dx.doi.org/10.1002/ab.21433.

22. Nunes F, Figueiredo M, Barba P, Emmel M. Retratos do cotidiano de meninos de cinco e seis anos: a atividade de brincar. Cad Ter Ocup UFSCar. 2013;21(2):275-87. http://dx.doi.org/10.4322/cto.2013.029. 